\title{
The Role of Social Influence in Purchasing Sports Apparel
}

\author{
By Swee Seng Chew ${ }^{*}$ \\ Ho Keat Leng ${ }^{\dagger}$
}

\begin{abstract}
The marketing of sports apparel is competitive with large amounts of advertising dollars spent in influencing consumer choice. The aim of this study is to establish whether a consumer is susceptible to social influence in the purchase of sports apparel. In particular, the study aims to establish if there is any difference between consumers of different genders and levels of sports involvement. A convenience sample of 116 respondents found that consumers are susceptible to informational and utilitarian influence but not value-expressive influence. The findings further suggest that consumers of the male gender and who are highly involved in sports are more likely to be influenced by informational influence as compared to consumers who are female and who are less involved in sports.
\end{abstract}

Keywords: Social Influence, Sports Involvement, Sports Apparels

\section{Introduction}

Consumer spending on sports apparel and athletic footwear in the United States in 2005 has been estimated to be US $\$ 40$ billion and US $\$ 16$ billion respectively (Milano and Chelladurai 2011). In addition, the global sports apparel market has been estimated to grow from US $\$ 132$ billion in 2011 to US $\$ 171$ billion in 2018 (Statista 2015).

Demand for sports apparel is driven by an increase in sports participation among the general population and the growing acceptance of sports apparel in daily wear. Besides athletes who are buying sports apparel to enhance their performance in sporting activities, other consumers are also buying sports apparel for outside sports use. Sports apparel companies have responded by spending large amounts of advertising dollars to influence consumer choice. This is led by global brands including Nike and Adidas. A large number of new entrants, for example Li-Ning from China, are also spending advertising dollars to gain brand awareness and market share.

Sports apparel is selected on a variety of product attributes including fit, aesthetics, design and the material used (Chae et al. 2006, Dickson and Pollack 2000, Scheerder et al. 2011). Other than product attributes, consumer choice is also influenced by other situational and demographic factors (Girard 2010). As a fashion product, sports apparel purchases are conspicuous and as such, they are more likely to be susceptible to social influences (Zhou and Wong 2008). In some

\footnotetext{
* Student, Nanyang Technological University, National Institute of Education, Singapore.

$\dagger$ Assistant Professor, Nanyang Technological University, National Institute of Education, Singapore.
} 
cases, the choice of a particular brand, type or colour of sports apparel can serve as a mean to create an identity for the wearer and an indication of membership in a group (Chae et al. 2006, Dickson and Pollack 2000, Bae 2011). Consequently, sports apparel companies have sought to communicate both product attributes and the desirability of their brands in social settings in their advertisements.

The aim of this study is to examine the extent of social influence in purchasing sports apparel. In particular, this study will also examine for differences in the extent of social influence across consumers based on their level of involvement in sports and demographics. This will allow an understanding of the role of social influence in the purchase of sports apparel and aid advertisers to design more effective communication with their target consumers.

\section{Literature Review}

Social influence can affect the consumers' buying decisions as humans learn to rely on others' perception and judgment as sources of evidence. In particular, the more uncertain a person is about the correctness of his judgment, the more likely he is susceptible to social influences in making his judgment (Burnkrant and Cousineau 1975, Deutsch and Gerard 1955).

Social influence can be categorised into informational and normative social influence. Informational social influence is defined as an influence to accept information obtained from another as evidence about reality (Deutsch and Gerard 1955). When consumers need to make an informed choice, they perceive the opinions or usage of products by others as credible proof of a product's quality or characteristics. As such, they are influenced in their purchase decision through the opinions of others (Lord et al. 2001, Yayli and Bayram 2012).

On the other hand, normative social influence is defined as an influence to conform to the positive expectations of another (Deutsch and Gerard 1955). This can be further categorised into value expressive and utilitarian influences. Value expressive reflects the consumer's desire to enhance self-image by association with a reference group. In contrast, utilitarian influence is reflected through consumers' attempts to comply with the expectations of others to achieve rewards or avoid punishments (Bearden et al. 1989, Park and Lessig 1977, Burnkrant and Cousineau 1975).

Although value-expressive and utilitarian influences are conceptually different, they have been found to be quite similar and difficult to distinguish in some studies. In part, this is because they are likely to coexist within the same sources. A reference group which a consumer desire to associate with, is also likely to simultaneously articulate acceptable norms, and mete out rewards and punishments accordingly (Lord et al. 2001).

Many studies have shown that social influence has an effect on consumer behaviour (Burnkrant and Cousineau 1975, Pincus and Waters 1977, Lord et al. 2001). In particular, normative social influence is stronger in conspicuous product categories (Lord et al. 2001, Zhou and Wong 2008). This is because conspicuous product categories allow the choice of brands and other product 
characteristics to be displayed and judgment on the appropriateness to be made by other people. Through the process of consumer socialisation, consumers are susceptible to normative influence through their peers and friends in terms of brand and product choice (Lachance et al. 2003). Consumers who desire to be part of a reference group or to comply with the expectations of members of the group will need to make purchase decisions of conspicuous products within the expectations of the group.

As a fashion product, sports apparel is considered conspicuous. Brand names play an important role in affecting consumer choice for sports apparel (Dickson and Pollack 2000). They not only reflect the choice of the individual consumer but more importantly, in a cohesive group, visibly indicates membership and shared beliefs of the group (Chae et al. 2006). Hence, it is expected that normative influence has an effect on consumer behaviour in the purchase of sports apparel. However, this effect may be limited if the product is relatively new to the market (Belleau et al. 2007).

The strength of social influence also differs across consumers (Park and Lessig 1977, Girard 2010, Lord et al. 2001). Consumers who are highly involved in fashion are interested to know more about fashion. As such, they are likely to spend more time searching for the appropriate fashion products and are more susceptible to informational influence (Chae et al. 2006).

Similarly, it is expected that consumers who are high in sports involvement will spend more time searching for the correct sports product or equipment as they are active product information seekers (Tsiotsou 2006, Dickson and Pollack 2000, Ko et al. 2008). Hence, consumers with higher levels of sports involvement are more likely to be susceptible to social influence in the form of informational influence (Lord et al. 2001). In contrast, consumers who are less involved in sports are likely to be less interested in sport products. They are not active product information seekers and are thus less likely to be susceptible to informational influence.

This perhaps explains the popularity in using athletes in the marketing campaigns of sports apparel. Endorsements by sports celebrities have a positive influence on consumption behaviour. They can generate favourable word-ofmouth and purchase intention for the brands (Bush et al. 2004, Yoon and Choi 2005). This is because besides being admired for their celebrity status, sports celebrities can also influence purchase decisions through the perception of their expertise in the sport (Dix et al. 2010). As such, the effectiveness of sports celebrities in advertisements is limited to the fit between the celebrity athlete endorser and the endorsed product (Kim and $\mathrm{Na} 2007$ ).

The literature also shows that demographic differences exist in the extent of social influence on the consumer decision-making process (Girard 2010). Specific to sports apparel, although both genders are likely to be influenced by their peers in the consumer decision-making process, it was interesting to note that fathers has an influence in brand choices for female consumers but not for male consumers (Lachance et al. 2003). In addition, athletic role models are more likely to generate favourable word-of-mouth and purchase intention among female consumers as compared to their male counterparts (Bush et al. 
2004). However, a more recent study showed that difference between genders is limited to only complaint behaviours (Dix et al. 2010).

The above discussion showed that social influence has an effect on consumer behaviour. In particular, as sports apparel is considered conspicuous products, social influence in the form of normative influence is likely to play a role in the purchase of sports-related goods. Given that sports apparel is also purchased for enhancing performance, it is expected that informational influence will also affect the consumer choice especially among those who are highly involved in sports. As the literature also suggests that there are demographic differences in the extent of social influence, this study will also examine gender differences in the purchase of sports-related products.

\section{Methodology}

The survey instrument consisted of three sections. In the first section, to test for social influence, 13 items on a 7-point Likert scale item ranging from strongly disagree to strongly agree were adapted from an earlier study examining the effect of social influence. Items 1 to 4 measured informational influence; items 5 to 8 measured utilitarian influence; and items 9 to 13 measured value-expressive influence (Girard 2010). In this survey instrument, the sports-related product used in the research was sports shoes. This is because sports shoes are more likely to be purchased by the general population as opposed to specific athletic wear or equipment. The questions used in the survey instrument are as follows.

1. I would search information about various brands and models from an association of professionals or an independent group of experts.

2. I seek information from those who work in the sports industry on how Brand A's performance compares to Brand B's.

3. The brand of sports shoes that I select is influenced by whether the brand is used by professional athletes.

4. My choice of sports shoes is influenced by other consumers' word of mouth or some evaluation reports from an independent testing agency (e.g., online reviews).

5. My friends' evaluation and preference will influence my choice.

6. Other people's recommendation may influence my final decision.

7. The preferences of family members can influence my choice of running shoes.

8. To satisfy the expectations of classmates or fellow work associates, my decision to purchase running shoes is influenced by their preferences.

9. I tend to choose those brands or models that will enhance my image in the others' eyes.

10. I feel that those who purchase or use the running shoes of a particular brand or model possess characteristics which I would like to have.

11. I feel that it would be nice to act like the type of person whom advertisements show wearing the running shoe of a particular brand or model. 
12. I think that the people who purchase the running shoes of a particular brand or model are sometimes admired or respected by others.

13. Using running shoes of a particular brand or model helps me show others who I am, or who would like to be (such as a fit and active person, etc).

The second section of the survey measures sports involvement using a 3item, 7-point Likert scale. These items are adapted from an earlier study. Sport involvement means the love of and bond with sports. It is considered the cognitive affiliation towards sports as opposed to sport participation which measures the actual behaviour in sports (Gwinner and Swanson 2003).

1. Sports are very important to me.

2. I think about sports all of the time.

3. I watch sporting events whenever I can.

The scale was found to be reliable in the earlier study with Cronbach's alpha coefficient reported at 0.87 (Gwinner and Swanson 2003). For this study, the scale was also found to be reliable with a Cronbach's alpha coefficient of 0.87 .

The last section consists of demographic questions including gender and age. The data collected from this section will be used to describe the respondents' profile.

A convenient sample of 168 respondents was drawn from the researchers' network of friends on a social network site. The survey instrument was distributed via email of which 117 respondents returned the survey. One survey was incomplete and was taken out of the analysis. The effective response rate was 116 respondents or $69 \%$. The respondents were between 19 to 28 years of age with a mean of 22.6 years of age. The proportion of female respondents in the sample was $49.1 \%$ or 57 respondents.

\section{Findings}

Table 1 shows the respondents' agreement with the statements on social influence in the purchase of sports shoes. The items are on a 7-point Likert scale with a mid-point of 4 . The findings show that respondents generally agree that their purchase decision is influenced by informational factors $(M=4.47$, $\mathrm{SD}=0.79$, 95\% CI: 4.32 to 4.61 ). At a lower level of agreement, respondents agree that their purchase decision is also influenced by utilitarian factors $(\mathrm{M}=4.17, \mathrm{SD}=0.67,95 \% \mathrm{CI}: 4.05$ to 4.30$)$. However, respondents are not likely to be affected by value-expressive influence as the mean score was less than the mid-point of the 7-point scale ( $\mathrm{M}=3.54, \mathrm{SD}=0.75,95 \% \mathrm{CI}: 3.41$ to 3.68). This suggests that in the decision to purchase sports shoes, consumers are influenced by others in the information that they provide and the need to conform to the expectations of others, but not by the desire to enhance selfimage by associating with the reference groups. 
Table 1. Social Influence in Purchasing Sports Shoes

\begin{tabular}{|l|c|c|c|c|}
\hline & Mean & SD & Maximum & Minimum \\
\hline Informational & 4.47 & 0.79 & 6.50 & 2.75 \\
\hline Utilitarian & 4.17 & 0.67 & 5.75 & 1.50 \\
\hline Value-Expressive & 3.54 & 0.75 & 5.60 & 1.00 \\
\hline
\end{tabular}

Note: $\mathrm{n}=116$.

The relationship between informational, utilitarian and value-expressive influences was investigated using the Pearson product-moment correlation coefficient. There was a medium, positive correlation between utilitarian and value-expressive influences, $r=0.33, n=116, p<0.01$ (Table 2 ). This concurs with earlier studies which suggest that although value-expressive and utilitarian influences are conceptually different, they are likely to coexist within the same sources and can be difficult to distinguish from each other (Lord et al. 2001).

Table 2. Correlations between Informational, Utilitarian and Value-Expressive Influence

\begin{tabular}{|l|c|c|c|}
\hline & Informational & Utilitarian & Value-Expressive \\
\hline Informational & - & 0.04 & 0.16 \\
\hline Utilitarian & & - & $0.33^{*}$ \\
\hline Value-Expressive & & & - \\
\hline
\end{tabular}

Note: ${ }^{*} \mathrm{p}<0.01$ (2-tailed).

To examine whether there were differences in social influence across gender and sport involvement, independent t-tests across the sub-groups were performed. The skewness values of Informational, Utilitarian and Value-Expressive influences were from -0.81 to 0.27 . The kurtosis values of the variables were from 0.04 to 2.19. As the sample size was large, the detrimental effects of nonnormality would be reduced and parametric tests would be acceptable in this case. More importantly, visual checks of histogram and normal probability plots showed adherence to reasonable levels of normality (Hair et al. 2010, Pallant 2010). Table 3 shows the differences in social influences across the genders.

Table 3. Gender Differences in Social Influence in Purchasing Sports Shoes

\begin{tabular}{|l|c|c|c|}
\hline & Male $^{\mathbf{a}}$ & Female $^{\mathbf{b}}$ & $\boldsymbol{t}_{\text {-value }}$ \\
\hline Informational & 4.67 & 4.26 & $2.87^{*}$ \\
\hline Utilitarian & 4.09 & 4.25 & -1.34 \\
\hline Value-Expressive & 3.58 & 3.51 & 0.56 \\
\hline
\end{tabular}

Note: ${ }^{\mathrm{a}} \mathrm{n}=59,{ }^{\mathrm{b}} \mathrm{n}=57 ;{ }^{*} \mathrm{p}<0.01$.

The independent t-tests showed that male consumers (M=4.67, $\mathrm{SD}=0.78)$ are more likely to be influenced by other people in providing information on sports shoes as compared to female consumers $(\mathrm{M}=4.26, \mathrm{SD}=0.74 ; t(114)=2.87, p<0.01)$. The magnitude of the difference in the means was medium $(d=0.54)$ (Cohen 1988). 
However, there are no significant differences between the genders in utilitarian and value-expressive influence. Both genders are equally likely to be influenced by others through utilitarian influence. The two groups are also less likely to be influenced by others through value-expressive influence.

Respondents in this study reported a low level of sport involvement $(\mathrm{M}=3.85, \mathrm{SD}=1.32) .59$ respondents obtained an average sport involvement score of less than the scale mid-point of four and were categorised into the low sport involvement group $(\mathrm{M}=2.79, \mathrm{SD}=0.09)$. The remaining 57 respondents were categorised into the high sport involvement group $(\mathrm{M}=4.95, \mathrm{SD}=0.11)$.

An independent $\mathrm{t}$-test was conducted to compare the means of informational, utilitarian and value-expressive influence for the low and high sports involvement groups. Table 4 shows the differences in social influence in purchasing sports shoes across the different levels of sports involvement.

Table 4. Differences in Social Influence in Purchasing Sports Shoes Across Levels of Sports Involvement

\begin{tabular}{|l|c|c|c|}
\hline & $\begin{array}{c}\text { Low Sports } \\
\text { Involvement }^{\mathbf{a}}\end{array}$ & $\begin{array}{c}\text { High Sports } \\
\text { Involvement }^{\mathbf{b}}\end{array}$ & t-value \\
\hline Informational & 4.27 & 4.67 & $-2.84^{*}$ \\
\hline Utilitarian & 4.25 & 4.10 & 1.23 \\
\hline Value-Expressive & 3.52 & 3.57 & -0.38 \\
\hline
\end{tabular}

Note: ${ }^{\mathrm{a}} \mathrm{n}=59,{ }^{\mathrm{b}} \mathrm{n}=57 ;{ }^{*} \mathrm{p}<0.01$.

Consumers who are highly involved in sports are more likely to be influenced by other people providing information on sports shoes $(M=4.67$, $\mathrm{SD}=0.81)$ as compared to consumers who are less involved in sports $(\mathrm{M}=4.27$, $\mathrm{SD}=0.71 ; t(111)=-2.84, p<0.01)$. The magnitude of the difference in the means was medium $(d=0.53)$ (Cohen 1988). There are no significant differences between the two groups in utilitarian and value-expressive influence. This indicated that both groups are equally likely to be influenced by others through utilitarian influence. In addition, both groups are equally unlikely to be influenced by others through value-expressive influence as they scored a mean of less than the neutral point of 4 .

\section{Discussion}

The above show that in the purchase of sports apparel, social influence plays a role in the consumer decision-making process. Consumers are affected by others through informational and utilitarian influence. In addition, consumers who are of male gender or highly involved in sports are more likely to be influenced by others through informational influence as compared to consumers who are of female gender or less involved in sports.

The literature review suggested that in selecting sports apparel, consumers are looking for products that not only can enhance their performance in the sport, but also in some cases, form an identity or indicate membership in a reference group. Given that the product in this study is sports shoes, it is not unexpected that 
respondents in this study are influenced by others in seeking information from them on the choice and selection of sports shoes. This is because the choice of sports shoes in many sports has a direct impact on sports performance. The wrong type of sports shoes can reduce the performance of the athlete and in the worst case scenario, cause injury to the athlete. To a lesser extent, respondents in this study also found that utilitarian influence plays a role in the consumer decisionmaking process. This concurs with the literature that in some cases, choice and selection of sports products is influenced by membership in a group. Selecting the appropriate brand of sports shoes is also dependent on the expectations of the reference group.

Consumers who are high in sports involvement are likely to be concerned on how the sports product enhances their performance in the sport. As such, they are active seekers for product-related information and may be more influenced by others who possess such information or who are perceived as experts.

Among male consumers, social influence is also more likely to have a larger effect through informational influence. Earlier studies have indicated that males are more likely to be highly involved in sports (Leng et al. 2014, Denham 2010, Scheerder et al. 2011). As such, similar to the above arguments, male consumers are more likely to be concerned on the enhancement of sport performance by the sports product and are thus more likely to seek information on the brands and products.

Findings from this study suggest that sports marketers should be aware that in marketing sports products, social influence in the form of informational and utilitarian influence can play a role in influencing consumer choice. As such, marketing campaigns should focus on the use of experts in providing information on the sports products and indicating the acceptance of such sports products by the relevant reference groups. This is because the findings from this study suggest that marketing campaigns that attempt to influence consumer choice through valueexpressive influence may be limited in effect.

In addition, the study also suggests that marketers need to adapt their marketing campaigns across demographic and psychographic segments. For sports products that are targeted at male or highly involved consumers, there is a greater need to focus on the use of experts and the provision of product-relevant information. Marketing to the serious athlete will require marketing strategies that are different from those aimed at the general population. As such, marketers must identify the most appropriate means to communicate and influence consumers' choice.

\section{Conclusions}

The findings from this study showed that social influence can affect consumers' decision in sports-related products in the form of informational and utilitarian influence. The effect of informational influence is also more pronounced among consumers of the male gender and who are highly involved in sports. 
However, as the respondents in this study are limited to a convenience sample of relatively young adults, it is possible that individuals with different demographics may behave differently. Hence, this remains a limitation of this study and warrants future study involving a more representative sample. In addition, the research product used in this study is sports shoes. Whether there are differences in other types of sports apparel remains to be tested in future studies.

\section{Acknowledgments}

We wish to acknowledge the funding support for this project from Nanyang Technological University under the Undergraduate Research Experience on CAmpus (URECA) programme.

\section{References}

Bae S (2011) Decision-making Styles in Purchasing Sport Products: An International Comparison Between American and Korean College Students. In H Dolles, S Söderman (eds.), Sport as a Business (35-52). Palgrave Macmillan.

Bearden WO, Netemeyer RG, Teel JE (1989) Measurement of consumer susceptibility to interpersonal influence. Journal of Consumer Research 15(4): 473-481.

Belleau BD, Summers TA, Xu Y, Pinel R (2007) Theory of Reasoned Action Purchase Intention of Young Consumers. Clothing and Textiles Research Journal 25(3): 244-257.

Burnkrant RE, Cousineau A (1975) Informational and normative social influence in buyer behavior. Journal of Consumer Research: 206-215. DOI:http://dx.doi.org/ $10.1086 / 208633$.

Bush AJ, Martin CA, Bush VD (2004) Sports celebrity influence on the behavioral intentions of generation Y. Journal of Advertising Research 44(1): 108-118.

Chae M-H, Black C, Heitmeyer J (2006) Pre-purchase and post-purchase satisfaction and fashion involvement of female tennis wear consumers. International Journal of Consumer Studies 30(1): 25-33.

Cohen J (1988). Statistical Power Analysis for the Behavioral Sciences. Lawrence Erlbaum.

Denham BE (2010) Correlates of Pride in the Performance Success of United States Athletes Competing on an International Stage. International Review for the Sociology of Sport 45(4): 457-473.

Deutsch M, Gerard HB (1955) A study of normative and informational social influences upon individual judgment. The Journal of Abnormal and Social Psychology 51(3): 629-636.

Dickson MA, Pollack A (2000) Clothing and identity among female in-line skaters. Clothing and Textiles Research Journal 18(2): 65-72.

Dix S, Phau I, Pougnet S (2010) "Bend it like Beckham": the influence of sports celebrities on young adult consumers. Young Consumers: Insight and Ideas for Responsible Marketers 11(1): 36-46.

Girard T (2010) The Role of Demographics on the Susceptibility to Social Influence: A Pretest Study. Journal of Marketing Development and Competitiveness 5(1): 9-22. 
Gwinner K, Swanson SR (2003) A model of fan identification: Antecedents and sponsorship outcomes. Journal of Services Marketing 17(3): 275-294.

Hair JF, Black WC, Babin BJ, Anderson RE (2010) Multivariate Data Analysis. New Jersey: Pearson.

Kim Y-J, Na J-H (2007) Effects of celebrity athlete endorsement on attitude towards the product: the role of credibility, attractiveness and the concept of congruence. International Journal of Sports Marketing \& Sponsorship 8(4): 23-33.

Ko Y-J, Kim K, Claussen CL, Kim T-H (2008) The effects of sport involvement, sponsor awareness and corporate image on intention to purchase sponsors' products. International Journal of Sports Marketing \& Sponsorship 9(2): 79.

Lachance MJ, Beaudoin P, Robitaille J (2003) Adolescents' brand sensitivity in apparel: influence of three socialization agents. International Journal of Consumer Studies 27(1): 47-57.

Leng HK, Kuo TY, Baysa-Pee G, Tay J (2014) Make me proud! Singapore 2010 Youth Olympic Games and its effect on national pride of young Singaporeans. International Review for the Sociology of Sport 49(6): 745-760.

Lord KR, Lee M-S, Choong P (2001) Differences in Normative and Informational Social Influence. Advances in Consumer Research 28(1): 280-285.

Milano M, Chelladurai P (2011) Gross domestic sport product: The size of the sport industry in the United States. Journal of Sport Management 25(1): 24-35.

Pallant J (2010) SPSS Survival Manual. 4th ed. Maidenhead: Open University Press.

Park CW, Lessig VP (1977) Students and housewives: Differences in susceptibility to reference group influence. Journal of Consumer Research 4(Sept.): 102-110.

Pincus S, Waters LK (1977) Informational social influence and product quality judgments. Journal of Applied Psychology 62(5): 615-619.

Scheerder J, Vos S, Taks M (2011). Expenditures on sport apparel: Creating consumer profiles through interval regression modelling. European Sport Management Quarterly 11(3): 251-274.

Statista (2015) Total revenue of the global sports apparel market from 2011 to 2018 (in billion US dollars). Retrieved from goo.gl/P3CwxH. [Accessed: 21 September 2015]

Tsiotsou R (2006) The role of perceived product quality and overall satisfaction on purchase intentions. International Journal of Consumer Studies 30(2): 207-217.

Yayli A, Bayram M (2012) e-WOM: the effects of online consumer reviews on purchasing decisions. International Journal of Internet Marketing and Advertising 7(1): 51-64.

Yoon S-J, Choi Y-G (2005) Determinants of successful sports advertisements: The effects of advertisement type, product type and sports model. The Journal of Brand Management 12(3): 191-205.

Zhou L, Wong A (2008). Exploring the influence of product conspicuousness and social compliance on purchasing motives of young Chinese consumers for foreign brands. Journal of Consumer Behaviour 7(6): 470-483. 